\title{
Effective social constructivist approach to learning for social studies classroom
}

\author{
Rajendra Kumar Shah
}

Kailali Multiple Campus, Teaching Faculty, Nepal

\begin{abstract}
The major aim of the present study is to address the question do we have any alternative of deficit model of teaching learning? For this purpose, teachers of social studies teachers were interviewed and teaching learning practices of social studies has been evaluated. The researcher adopts the theoretical underpinnings of socio-cultural approach to learning and tries to design and execute constructivist teaching learning setting for teaching social studies. It emerges from the analysis of these constructivists pedagogic settings that it helps to develop and sustain a culture of inquiry in the classroom where the strong interface between students' everyday knowledge and school knowledge take place. The paper concluded that for moving deficit model of teaching learning, knowledge should be viewed as coconstructed, negotiated and situated entity, knower should have agency and the voice in process of knowing and the process learning should be dialogic.
\end{abstract}

Keywords: Social studies; Funds of knowledge; Social constructivism

Article History: Submitted 12 January 2019; Revised 2 June 2019; Published online 8 August 2019

\section{Introduction}

History of education in Nepal is very short. Only after the establishment of democracy, educational development takes place in Nepal. The first educational commission in Nepal, National Education Planning Commission (NNEPC), submitted its report 'Education in Nepal' in 1956 (College of Education, 1956). This report surveyed the extent and nature of education in Nepal, collected perceptions of Nepalese people and analyzed need for education in Nepal in the first part of the report. Nepal National Education Planning Commission, 1956 outlined curricular, instructional and assessment plan for the primary level. The commission conceived education to be a guiding experience in living. Children should not be forced to step into another world as they cross the threshold of the school. The report argued that children learn more effectively, more rapidly, and more permanently when they take an active part in the learning process. Passive learning rarely leads to dynamic, active, self-directed behaviour, or develop responsibility and leadership. Therefore, the primary school should follow the activity or project method in which pupils are taught to identify their problem, plan and direct their solutions, and evaluate the results for themselves. When asked, a pupil should know what s/he is doing, why s/he is doing

Address of Corresponding Author

Rajendra Kumar Shah, Kailali Multiple Campus, Dhangadhi, Sub-Metropolitan City, Kailali, Province No.7, Nepal.

$\triangle$ drrajendrakumarshah @gmail.com

0000-0003-0533-1338

How to cite: Shah, R. K. (2019). Effective social constructivist approach to learning for social studies classroom. Journal of Pedagogical Research, 3(2), 38-51. 
particular activity and s/he should be interested in the activity. Cooperative planning, problem based activities; life related projects make the classroom a workshop where students learn by doing and teachers should act as a facilitator.

All Round National Education Committee (ARNEC) 1961, the second national education Commission in Nepal, emphasized that a good education should inculcate good thinking, perceptions, reflection, views in children. Teaching method should be based on the findings related to body, heart, brain and soul. Teaching methods at the primary education should focus on the development of students' concentration, analytical skills, listening, memorization, etc. Most important of them is the concentration. Primary education should be provided through oral, activity, drawing and examples. Undue textbook load should be discouraged. Accordingly, the commission suggested grade-wise curriculum with content outline in general (MOE, 1961). In 1971 The National Education System Plan (NESP) was commissioned to draw a five year plan for 1971-1976 which emphasized and worked in the designing of national level curriculum and textbook development (MOE, 1971). The Commission focused more on institutionalization of the education system, nationalization of schools and uniformalization of curriculum and textbooks, but there are no specific recommendations for the teaching methods. Though the teaching methods in use then were termed to be extremely old-fashioned, there has been only cursory suggestions on the appropriate teaching methods which were suggested to be developed through education improvement and research projects, and experiment and extend new teaching methods. Report of National Education Commission 1992, reviewed and discussed entire education system (NEC, 1992). The commission pointed out that education system in vogue has not been able to meet the national, social and individual requirements. It was neither interesting to the children, nor was suited to the rural environment. At the first place teacher refrained from taking class and even when they took class, its quality and content was theoretical and bookish. Students were rather made to learn by rote and what students learn was devoid of meaning. It was deprived of realistic activities and theory was never applied in practice. The commission recommended fundamental objective of primary education as the development of the inborn abilities of the children under a pupil-centred system; to pay attention to providing practical knowledge about agriculture and environment; to orient towards hygiene and sanitation through the medium of practical activities, etc. These examples show that the commission emphasized child centred education at the primary level.

The Report of the High Level National Education Commission (HLNEC, 1999) reviewed overall education system and identified main problems and issues related to fourteen different themes. Among these problems and issues were poor quality of primary education, faulty evaluation system, lack of relevancy of education to the students, low quality of teachers' standard and qualification, and incompatible medium of instruction. This report suggested streamlining objectives of primary education, adopting liberal promotion and continuous assessment system, upgrading qualifications of teachers, improving curriculum and textbooks, teaching in native languages, and use reformative teaching. As the teaching practices were not effective, it was suggested to use reformative teaching practices to identify the weakness in teaching methods, improve teaching accordingly and attract the students to classes.

More consorted effort was put on to improve quality of primary education with Primary Education Project which came into effect in 1984 (CERID, 1989). This project initiated formal planning for programme implementation at the national level. First the project was implemented in the six districts of the country and then gradually covered nation-wide. This project was designed to a) achieve a low-cost qualitative improvement in primary education, and b) strengthen the administrative and technical capacity of the sector. This project aimed at improving the competence of teachers to raise the quality of instruction in the primary schools through training of teachers and supervision of classroom teaching. Teachers of cluster schools were provided 12 days training focussing on the subject matter and then 10 days training focussing on the development and the use of educational materials at two phases. Development and use of 
instructional materials, lesson planning and subject teaching methods were covered in the training programme.

Primary Education Project was followed by The Basic and Primary Education Project 1991-2001. In 1996, the project was updated based on the recommendations made by the Mid Term Review and was designed for the period of 1997-2002. Basic and Primary Education Project Master Plan 1991-2001 (MOEC, 1991) emphasized on dissemination of intents and expected outcomes and synchronisation of curriculum and textbook development to improve quality of education. In case of examination reforms it was planned to use continuous assessment of pupil progress in improving instructional standards, promoting liberal promotion in early grades, implementation of a national primary education assessment programme and use of its results. Regarding teacher training, the plan emphasized to match training programmes with the training needs of the primary school system (e.g. grade teaching and multi-grade teaching); focus initial training of inservice teachers on developing essential pedagogical competencies; adopt modular training approach to provide optimal training to in-service teachers; etc. The Basic and Primary Education Master Plan 1997-2002 (MOE, 1997) developed a comprehensive plan covering various aspects related to primary education. In relation to the pedagogical improvement, the plan emphasized on teacher training, improved and continuous student assessment, enhanced physical and learning environment, and physical rehabilitation of schools. Similarly, it was emphasized that Curriculum Dissemination Programme would be conducted with teacher's guide as the main tool of dissemination training. The expected outcomes were-1) teachers be fully oriented on the use of teacher's guides and develop an inclination to use them, and 2) teachers be able to use appropriate method of teaching to achieve the objectives of the lessons. As teachers would be normally expected to follow the teaching techniques used during the training period while they teach in their classes/schools, teachers should be required to practise what they teach and preach about the effective methods of teaching at the time of training. The plan stated that almost fifty percent of the training on pedagogy should be conducted through apprentice method and emphasis was on use of methods and techniques for the learner centred approach.

Programme Implementation Plan for BPEP-II, 1999-2004 (MOE, 1999) viewed curriculum renewal and assessment, and teacher training and professional support as major components for improving learning achievement of the students. This plan highlighted several policy issues and strategies to create a better learning environment emphasizing on increasing the daily attendance of teachers and students; enrolling only appropriate age children at grade I; creating a healthy, safe and pleasant school environment; timely distribution of curricular materials; increasing the grade promotion and school retention rates; reducing overall class size; improving learning especially in grades 1 to 3; and providing teachers with adequate, appropriate training and classroom support. Emphasis was put on demand driven annual recurrent in-service training, whole school approaches to school quality development, training content that focuses on the learning needs and styles of young children and professional support through school cluster based activities and mentoring in classrooms from Resource Persons and other teachers. Further support on basic and primary education in Nepal was started in 2002 and plan was forwarded for 'Education for All' (EFA). Education for All National Plan of Action Nepal 2001-2015 (MOES, 2003) outlined its framework on the basis of six major goals set by Dakar Forum for the Year 2015. Quality education, meeting learning needs, making curriculum more practical and relevant to day to day life, life skills, improving school environment, teaching in mother tongue, formative assessment, etc. were emphasized. Education for All 2004-2009 Core Document (MOES, 2003) set three main objectives-a) ensuring access and equity in primary education, $b$ ) enhancing quality and relevance of primary education, and c) improving efficiency and institutional capacity of schools and institutions at all levels providing technical backstopping to schools. The Document envisioned 'A Child', 'A School', 'A Classroom', 'A Teacher' and 'A Community or District' by 2015. All children learn to become democratic citizens through relevant elements of life skills fulfilling the individual as well as the nation's requirements. Child is inquisitive to learn and has command over a level of 
knowledge comparable to children of the same age group in the global context. All Nepalese schools are efficient and deliver quality education in a safe, conducive and challenging environment for child learning and development. As for a classroom by 2015, it is envisioned that the classroom would be a stimulating learning environment, designed to meet the learning needs of all students and ensure that each student develops to their full potential.

National Curriculum Framework for School Education in Nepal was developed in 2005 for the first time (MOES, 2005). The framework discussed the need for a national curriculum framework; developed overall context and curricular concerns; forwarded visions, goals and guiding principles for curriculum; suggested school education objectives, curriculum structure and student assessment policy; and outlined strategy for implementing the national curriculum framework. It has been emphasized that teaching approaches need to place greater emphasis on the tools for seeking and processing knowledge rather than the actual knowledge itself. This requires active involvement of students in the learning process. While teaching, the students should be regarded as a constructor of knowledge. Curriculum should be implemented in a child friendly manner.

School Sector Reform Plan 2009-2015 (MOE, 2009), which is currently being implemented in Nepal, has covered Early Childhood Education and Development to higher secondary (grades 11 and 12) in its purview. This plan focuses on integration and consolidation of basic education, i.e. grades 1-8, with the goal to ensure equitable access to quality education through a right based approach and promotion of a child friendly environment in schools. It is emphasized employing flexible learning approaches to respond to diverse needs and to address learners' individual pace to learning as well as implementing continuous assessment and remedial support systems. In order to ensure better learning environment, availability of qualified and trained teachers, curriculum and textbook materials, teacher's time on task, extra-curricular activities and so forth. Meeting minimum enabling condition and setting norms and standards has also been emphasized. National norms and standards for input, process and learning outcomes have been defined which includes an environment for equitable participation, safe, secure and child friendly classroom, adequate instructional processes, and adequate number of qualified teachers.

Department of Education published Framework of Child Friendly School for Quality Education in 2010 which explained what a 'child friendly school' is; why it is required; aspects of child friendly schools, etc. This framework listed a Child Friendly School would provide childrenphysically, mentally and emotionally safe and healthy environment; learning environment and curriculum according to their interest, ability and level; non-discriminating environment; care for their health and safety; fearless and punishment free environment. The emphasis is on how to enrich and modify existing educational condition rather than initiating new programme for a child friendly school. It is viewed that school improvement plan development, working modality of school management committee, management of financial and physical resources, mobilization of community, teaching learning process, extra-curricular activities, etc. should consider children as a focal point in order to bring about immediate and visible changes. For this the framework has quantified minimum and expected indicators of different aspects of child friendly school.

\subsection{Prevailing Pedagogic Practices of Social Studies in Nepal}

Observations of the existing primary level Social Studies curriculum, textbooks and teacher's guide showed that teaching strategies and methods had been determined in the existing curriculum and textbooks and teachers' guide. But the classroom observation showed that teachers did not follow these teaching activities and methods mainly because curriculum and teacher's guide were out of access of the teachers. On the other hand, teaching learning methods developed in the curriculum and teachers' guides were not easily understandable and applicable. It was also observed that textbooks seemed to be the only teaching aid available to both the students and the teacher. It clearly showed that lecture and even only book reading were the teaching methods prevailing in the primary school in Nepal. Curriculum, textbooks and teachers' guides of the primary level Social Studies gave more emphasis on the learning of facts through memorization rather than 
understanding and application in the field. Teachings learning activities usually completed within the four walls of the classroom and their sole duty was getting the child through the annual examination. The tests were mainly for the text memorization, the same vicious circle continued year after year. Thus, the whole teaching and learning strategies even at primary level was examination centered focusing on learning of facts rather than brining about changes in students behaviour and analytical ability.

One of the major drawbacks of the existing primary level social studies curriculum was that detailed plan of the teaching learning strategies was not prescribed in the curriculum. At the same time, teachers also did not use the teaching learning methods prescribed in the curriculum. First of all, curriculum and teachers' guide were not accessible easily to all teachers. Secondly, the teaching learning methods designed in the curriculum were not easily understandable and applicable. Most of the teachers were untrained, and they required training in teaching methods and the use of the curriculum. These and other several reasons were seriously affecting the teaching learning process of the primary school in Nepal. This analysis clearly shows that there is a big gap between the teaching learning methods designed in the curriculum and teaching strategies adopted by the teachers of the primary school in Nepal.

It was observed during the classroom observation that most of the teachers did not use the instructional materials effectively. Instructional materials were confined to the textbook and a blackboard in most of the school. Indigenous and local materials were not used by all most of the teachers. In some schools, it was also observed that the white soil was used instead of the chalk quite effectively. It was one of the best examples of the proper use of the locally available materials. If the teachers are able to use these types of indigenous and locally developed materials, learning of the students will be effective and long lasting. Thus, it can be inferred that teaching methods and strategies prescribed in the primary level Social Studies were not fully used by the teachers. On the hand, these methods were not adequate and sufficient either.

Another major problem of the teaching learning process was that the content of the primary education Social Studies textbooks were also mainly based on only memorization of facts. Thus, evaluation was also nothing more than recalling the facts during the time of examination. Students' evaluation was done at the end of the session in the form of a written test either to promote or to detend the students in a particular class. Though the teachers sometimes evaluated the student through the internal assessment, but this did not count for the final examination. Observation, check list, rating scale, cumulative records and other innovative evaluation tools were out of the custom. This analysis demands that activities based and child centered teaching learning methods should be immediately used in the primary schools in Nepal to make the teaching learning more effective.

There is big gap between the teaching methods prescribed in the curriculum and the teaching strategies adopted by the primary level Social Studies teachers. Primary school teachers rarely used the activity based and child centered teaching learning methods. It was also observed that some teachers started their lesson only by announcing the topics whereas some teachers asked their students to open the relevant page of the textbook and read aloud. This was one of the most common methods used in the primary schools in Nepal. Actually, regarding the teaching learning process the teachers' communication was one way. In certain schools, oral interaction between the teacher and students was observed, but teachers' questions were mostly to recall the facts. The teacher had not made any contribution to raise the active participation of the students. Most of the teachers used the traditional methods of teaching learning process. They did not use modern teaching learning methods and aids.

\subsection{Using Learners' Social Funds of Knowledge for Teaching: Beyond Deficit Model}

I informally interviewed Social Studies teachers of a Basic School who were teaching the existing Social Studies textbooks. Their responses showed a different picture of the prevailing pedagogic practices of social studies. Most of the teachers argued that existing social studies textbooks do not 
provide appropriate knowledge base for the success in the future. For them, success in the future means to prepare and qualify various competitive exams.

The major aim of the introduction of these new textbook was to move beyond the encyclopaedic image of knowledge related to various aspects of social studies. However, such kinds of views shows that the social studies teachers still believe in information loaded curriculum that can be used for examination purposes. They do not understand the shifts brought to curriculum through the National Curriculum Framework. Further such kind of belief system influences their pedagogic strategies and impedes the implementation of new curriculum with its above mentioned essence. They also reported that these books have overestimated learner's capacity and learners are unable to understand the concepts such as diversity and discrimination. They believe that every learner can learn but they share a prejudiced view regarding learner in their school: learners (coming from lower socio-economic class) are lacking in knowledge base, they are not motivated to learn, and they are not getting any support at home. These responses are reflection of deeply rooted teacher's beliefs which follow the deficit model of learner and learning. The possible explanation of such responses lies in Moll et. al.'s (1992) argument, when the classrooms practices are disconnected from learner's everyday experience classroom instruction tend to be unidirectional, authoritative and monologic (pp. 62). Furthermore, it contributes in forming and reinforcing teachers believe that learners coming from poor and lower class background do not bring significant cultural capital with them.

At the next phase of my research work, I initiated to design and create a pedagogic setting with the aim to challenge these assumptions of teachers and developing a learning environment by acknowledging learner's agency and voices in classroom learning processes. I got theoretical support and insights from the previous researches. Studies done by Moll et. al. (1992) showed that children through their active participation in various social activities accumulate funds of knowledge. Their funds of knowledge are abundant and diverse as they actively participate in a vast and diverse arena of activities in their contexts (Moll et. al., 1992, Velez-Ibanez \& Greenberg, 1992). Rogoff ( 1998) identified that students' daily experiences is not a passive and inactive storage of information rather they use it to influence each others' actions or engage in shared thinking. It is also suggested that learner's social experiences can be used to engage the class and construct the knowledge based on learner's resources rather than on their deficits (Gonzalez \& Amanti, 1992).

Learner's everyday experience in the community is a legitimate source of knowledge, a kind of cultural capital that can be tapped by teachers to improve the pedagogic practices. These studies led me towards the theoretical underpinnings of Social Constructivism. Social Constructivism explains learning and knowing as a social process, situated in physical as well as socio-cultural context and distributed across person and tools (Brophy, 2002; Bruner, 1996; Lave \& Wenger, 1991; Vygotsky, 1987). Learning also involves negotiating understanding through dialogue or discourse shared by two or more members of the community who are pursuing shared goals (Brophy, 2002). The basic tenets of socio-cultural approach are: learners construct their own knowledge, participating in authentic activities and internalizing the tools of practices; learners are reflective beings, they can think and reflect on their lived experiences; social interaction/ dialogue plays a crucial role in learning. This perspective focuses on learning as sense making rather than on the acquisition of rote knowledge that exists somewhere outside the learner. It expands the horizons of teaching learning process and stretches it beyond content and curriculum transaction to establish a community of learner's who are engaged in process of knowledge construction. Against the above backdrop the present study aims to design and implement Social Studies lessons adopting the social constructivist approach to learning. The approach provides a scope for using learner's funds of knowledge as resource in classroom discourses. 


\section{Method}

\subsection{Research Design}

A qualitative method has been employed in the present study. Adopting an interpretive approach, descriptive research design, the present study was designed as a descriptive research. The study was conducted in the class sixth of a Basic School situated in Dhangadhi Sub-metropolitan city Kailali, Province no 7, Nepal. The sample was limited to Dhangadhi, Kailali, a town with residents from varied socio-economic backgrounds. Dhangadhi has a number of primary schools for young children, thereby providing the opportunity to study a representative sample. After collecting the list of all primary school form the office of Dhangadhi sub-metropolitan city, Dhangadhi Ma Vi was purposively selected for the present study. The students of the school who agreed to participate by singing the informed consent form were taught for the purpose of this study.

\subsection{Participants}

There were 30 students, including 20 boys and 10 girls in the class. Some of them belonged to migrant families, migrated from rural Area of the other districts such as Doti, Bajhang, Bajura, Achham, Dadeldhura, Darchula, Baitdi (name of the districts). Most of the parents of children are working as labourer as daily basis. As a teacher researcher, the researcher himself taught the class for a period of one month. The class was taught in the session of January 2018.

\subsection{Instruments}

A set of questionnaire and classroom activities record from were used as tools in the present study. First of all, questionnaire and classroom activities form were prepared through a thorough literature review by the researcher in order to develop the questionnaire. The drafts of the questionnaire and classroom activities form were presented to five experts who were in the field of social studies curriculum. The experts were requested to evaluate the questionnaire and classroom activities from in terms of whether or not it served the purpose and had any validity. In accordance with the feedback obtained from the experts, these drafts were revised and brought to the final form.

\subsection{Procedures}

As a teacher researcher, the researcher himself taught the class for a period of one month. The class was taught in the session of the 2018-2019. The major source of the data of the present study was participant observation. All the activities carried out in the classroom were audio recorded. As participant observer, the researcher also kept field notes of all activities. Later on all the audio recorded data were transcribed and content analyzed. The field note was used for the triangulation of the data. For conducting this study, activities for teaching social studies to class sixth students were designed and executed by the researcher. It was kept in mind, while designing these activities that the knowledge and understanding about society that learners bring to the classroom must be acknowledged. This aspect of activity makes it authentic and similar to real world problems. The role of learner is envisioned as an active and reflective person acting within a certain context. The teacher, acting as the guide and facilitator, establishes situations that promote communications between students and student and teacher-student. These activities provide scope for interaction, participation and negotiation that helps in creating learning opportunities for exploiting the learner's funds of knowledge.

\subsection{Data Collection and Analysis}

The interpretive research seeks to understand values, beliefs and meanings of social phenomena and thereby extracts an empathetic understanding of human social activities and experiences (Smith \& Heshsius, 1986). Interpretivists believe in the inseparability of understanding from interpretation. They see all social research as interpretive because all such research is guided by the researcher's desire to understand and interpret social reality. Interpretive paradigm assumes 
that there are no facts, only interpretations Therefore, this study, with the help of vignette, aims to explore students' perceptions, share their meanings and develop insights about the observed case (Bryman, 2008; Grix, 2010).

According to Creswell (2003), qualitative researchers make interpretations of the data by developing descriptions of events and processes, analysing data for category and theme development, that ultimately lead to conclusions that are based on trustworthiness and credibility about theoretical and individual's meanings, stating the lessons learned. This means that researchers screen the raw data through personal lenses that are situated within specific sociopolitical and historical theoretical orientations (Creswell, 2003; Freire, 1971; McLaren, 2003). Therefore, the researcher chooses the vignettes to present the findings of this study. There vignettes have been presented in the present study to present the real scenario of the actual classroom activities. The first vignette, a conversation between teacher and students, reflects the concept of diversity. Accordingly, in the second vignette, students are divided in the four groups in order to carry out various activities and in the third vignette, a case vignette was given to the class and the learners were asked to read it and when they had read it, questions were posed to them to generate discussion. The major activities carried out in the classroom and findings of the present study have been presented in the results section.

\section{Results}

In this section, preferred vignettes and reflections from their application process are presented one by one. The findings from the application process of vignette 1 are presented below.
Activity-1
Diversity
Vignette-I
Teacher : Good morning class.
Students : Good morning teacher.
Teacher : Why are you sitting alone Ram? Ragunath is also alone Why are not sitting with
him?
Ram : He is Chaudhary sir and he speaks his language.
Teacher : Okay. So your friend is Chaudhary.
Ram : (Laughs) yes sir. He is from rural village.
Teacher : But he is your friend. Are you not accepting him as a friend because he is Chaudhary?
Ram : No Sir, he is my friend.
Teacher : If that doesn't influence your relation with him then from where he comes and what he speaks should not make a difference.
Teacher : Whatever may be the name, cast, religion, living place, colour, all of you are friend because you are reading in the class.

Now, teacher starts another activity.

This activity aimed at discussing the diversity. The overview of activity is as follows:

- First of all, teacher draws a table. There were a number of columns on the table. The headings of the columns were: name, state, religion, language, food, festivals, dress and some specific cultural practices of their family. Some blank space was also provided so that they could fill any other relevant information about themselves. The teacher asked to write the name, state, religion...in the column. Once they finished working on their work, they were asked to share and discuss the details filled with their elbow partner. This helped them to highlight and appreciate the similarities and differences in the content which they had mentioned. 
- Secondly, they were then divided into groups of five and asked to talk for three to five minutes on major forms of diversity.

- Thirdly, the forms of diversity that came up after discussion were written on the blackboard.

- Finally, further discussion was generated around the issues that emerged.

The major forms of diversity generated during classroom discussion were: physical appearance (color, height etc), region, religion, caste, intelligence, social class, gender and language. Keeping in mind these forms of differences, it was discussed whether these forms of differences would enrich our feeling of living together or would create hindrance to it. They had classified these forms in two major categories.

In the first category, they mentioned region, language, food and dress, which they said contribute to enriching their routine experiences. They said that name, attire, food habits and language help to identify other peoples region, religion and caste. It enriches their experiences by introducing them to the diverse ways of dressing, eating habits and language. Although they said that this is their culture and it does not work as constrain in their interaction with others, yet, during discussion, many stereotype and prejudices of learners came up:

He is Chaudhary and speaks Chaudhary language.

He is from Doti. He speaks Doteli language.

He could not speak proper Nepali.

These kinds of stereotypes and prejudices are the challenges for social cohesion. Such points were taken into account and included in the classroom discussion. It is noteworthy, that issues/stereotype would not have come to the fore if learners personal social experiences were not discussed in the class.

In the second category they put religion, class, caste, intelligence and told that these forms of differences separate each other. During the discussion, students affirmed that a person from one religion and caste does not want to interact with a person of other religion and caste; a person who belongs to high class and caste hates people of lower class. After discussion, students came to the point that this is not Diversity but something else. Significant finding that emerged during the discussion was that caste and class were significant dimensions of differentiation. This was evident through the fact that most of the learners mentioned their caste and class in the untitled boxes. All the girls of the class mentioned their gender in the same box along with caste and class while none of the boys mentioned his gender.

During the class activity, it was observed that a significant category of discrimination i.e., differently able was missing. Therefore, they were given a case that if a person who is visually challenged, is admitted to their class, how would he/she feel? How would they behave with them? As soon as this case was put before them their quick response was 'what would he do in our school?' This response showed that such kind of mindset is a challenge for inclusion. Taking this statement as a vantage point, a further discussion was encouraged. At the end of the discussion, learners themselves started empathizing with their imaginary classmate. This activity not only brought out their understanding about social diversity and discrimination but also reflected their stereotypes and prejudice. In the present activity they, themselves came forth to discuss about the critical issues which impedes the social cohesion. The activity made them revisit their stereotype and reflect on their prejudice.

\section{Activity-2}

Rural Economy

Vignette-II 
In order to understand whether the everyday classroom transactions and pedagogy provide any scope to integrate the essentials of learning to live together with the concepts taught in the classroom. The following set of problems was given to the class and their responses on the same were sought.

The students were divided into groups. They were given a reflective exercise where they were supposed to plan economic activities for farmers who had already sown their crops for the season and had finished all tasks related to farming. The students were told that until harvesting, the villagers were facing the problem of seasonal unemployment. While planning the activities, they were guided to keep the following points in mind:

- The task should generate monetary benefits for the farmers.

- All the villagers who are capable and willing to work should be included/employed in these activities in some way or the other.

- Through these activities some social cause or purpose should also be served. Along with this, the task should provide scope for people to nurture and develop-care, brotherhood and cooperation among each of them.

The students were asked to present the individual ideas about the possible solutions and plan to the problem and suggested plan for farmers. Within the group, the learners got the opportunity not only to present their ideas but also to debate whether the plans suggested were feasible and would generate optimum monetary returns. They tried to find the possible solutions to alleviate the problems of seasonal unemployment of farmers. Students seemed keen and excited to work on the task as this activity provided them with scope to work in small groups. Further, they felt that the planning they were doing would be instrumental in providing employment to the unemployed villagers. They seemed to be driven by a sense of positive 'purpose' and saw themselves as thinking-contributing members of the society. They were also expected to present this to the entire class.

The solutions they shared clearly showed the clarity and insight hey had in understanding the problem. It is evident that the variety of suggestions and proposed economic activities thought out by the children were not restricted to the examples stated in their textbooks. This shows that while working in groups they go beyond the given information and put their ideas in a constructive way. During the observations, it was found that every group took time to arrive at a consensus. It is significant to note that none of the student showed a tendency to dominate the others while working in groups. Every one gave space to other members of the group to express their idea. When one child shared his/her idea, everyone else in the group listened to the idea and commented on it and finally all the group member arrived at the consensus regarding the most appropriate activity that they were going to present in the class. It is important to note that the children kept in mind the gender, the educational background and social status of people while allocating them work.

It can be inferred from this tendency that for them these factors decide the occupational trajectory of the individuals. While conducting the discussions it was further probed as to why only women should make toys? Or why only the rich people should finance? Or why only the educated villagers should manage finances and accounts? What are the implications of these for long term planning? This gave them a chance to come out of their comfort zones and think of a possible world that is free of biases and based on the principles of equality, fraternity and brotherhood.

\section{Activity-3 \\ Rural Municipality}

Vignette-III 
First of all, at the beginning of the class, a case vignette (from the book) was given to the class and the learners were asked to read it. Secondly, when they had read it, the following questions were posed to them to generate discussion: (1) what are the major issues discussed in the Rural Municipal? (2) What could be the other issues that can be discussed in the Rural Municipality? And (3) how does Rural Municipality arrive at any decision? These were only guiding questions for the discussion.

It emerged during the discussion that the learners knew that the Rural Municipality implements government plans such as preparing and repairing roads etc. Along with it, Rural Municipality also deals with people's personal matters such as land and property disputes, division of property and so forth. The focus of vignette and course content was to provide them with an idea that Rural Municipality works as local government. During the process, the learners raised these significant aspects of Rural Municipality, themselves, showing that they observe and are aware of what goes around them. They may not be direct participants in the process but they are aware of these.

Taking into account these points, they were asked to give some examples from their own lives where they had heard or seen any matter being addressed by the Rural Municipality. One student narrated his own experience to the class, which is as follows

Last year I went to my village. My uncle fought with my father and separated my family. My father went to the Chairman of Rural Municipality and requested him to intervene and divide the property in a fair manner. Then they brought some of their other people along with them and fairly divide the property.

When a learner was narrating the whole experience, he was not just describing a case but also a personal life experience. This made the other learners in the class aware of the functioning and role of the Rural Municipality. Along with this they were also able to understand the turmoil a family goes through when people fight and separate. The entire class also learnt as to how his family no more includes his cousins; they have become 'other' for him and his family. This process of separation made his uncle's family 'other' from his family.

It also emerged during the discussion that Rural Municipality takes decisions in consensus with all the members of the Rural Municipality and after listening to the arguments of both the sides. To elaborate it further and make the process of decision making more explicit, they were asked to highlight/hypothesize how the process of decision making would take place in a group? The learners came up with the following responses:

Every person will express his view. While he/she is expressing their views everyone else would listen to her. They may agree or disagree. In case of a disagreement, they will argue it out within the group. Gradually, this process will move further and the group will eventually arrive at a final decision, possibly which suits all or most. In this process everyone's voice(s) will be heard. Each idea is important. This whole decision making process looks at the welfare of the community as a whole and. It kept in mind that the decision should not harm anyone. Through this process of reflection, they came up with very relevant ideas.

This process could be followed while taking decision in group. But most of the students did not support this idea while making decisions in Rural Municipality.

In the case vignette it was shown that all the villagers are present in Rural Municipality meeting but during the classroom discussion many students argued as followed:

"But everyone does not go in the Rural Municipality meeting, only 'big shots' are called and only they discuss during the meetings." 
When probed as to whom do they consider influential? One of the learners said:

\begin{abstract}
Students-1 : Those who have lots of money, land and belong to upper caste.
Teacher : But according to constitution, everyone can participate in Rural Municipality meeting.

Students-2 : No Sir, only influential people attend Rural Municipality, I have seen it.

Teacher : Ok. tell me, who puts forth the views of the people who do not attend the Rural Municipality.
\end{abstract}

\title{
(This was followed by a silence in the class)
}

Teacher : Don't you think that if we have been given a right, then we should go and put forward our point.

The discussion was carried forward by probing further. During the discussion an effort was made that students reflect on these issues, critically. In this activity, it emerged that learners were aware of what was going on in the society. They knew the gaps between what was actually happening and what ought to be happening. They were also open to revisit and challenge their existing notions and construct fresh notions that seemed more appropriate and progressive. It was hoped that in the light of their lived experiences and reality, they would be enabled to think in a positive and critical manner. What also emerged through the classroom interaction was that the teacher's role was not cut short but he/she was allotted a key role in facilitating the teaching learning process. Teachers role is not only restricted to presenting the concepts but developing understanding and skills of critically reflecting on those concepts and connecting them with real issues; providing space for meaningful engagement and dialogue on social issues. While discussing those concepts she should help students understand the realities of societies by discussing the difference and diversity, there is a possibility to make them responsive human beings who accept multiple perspectives and people who are seen as others.

\section{Discussion and Conclusion}

Constructivism intends to refine students' knowledge, develop inquiry skills through critical thinking, and lead to students developing opinions about the world around them. According to Cannella and Reiff (1994) and Richardson, (1997) learning activities in a constructivist setting are characterized by active engagement, inquiry, problem solving, and collaboration with others. According to Zevin (2000), correct answers and single interpretations are de-emphasized in constructivist learning. McKay (1995) writes that the constructivist approach is skill and problem solving-based. Nuthall (2000) adds that the teacher needs to offer multiple perspectives and a variety of formats in which the information can be presented. Social Studies constructivist learning is enhanced when students begin processing what they have learned on multiple levels, which leads to higher level thinking and strays away from strict factual information; whereas in postcolonial conservative communities, socio-cultural constraints are imposed on the students, hindering the promotion of constructivist teaching learning in general, including Social Studies. According to Ediger (2000), 'Social Studies needs to use a variety of methods and procedures to assist each pupil to achieve as optimally as possible. Learners individually possess diverse learning styles and intelligences'.

It can be seen that in above mentioned narratives, the whole pedagogic practice begins with learners' understanding of various aspects of social studies, moves further with critical reflection by problem posing and providing space for reconstruction of prior assumptions beliefs and ideas of children. At the same time, learner's engagement and ownership in classroom pedagogic processes, teachers modelling the culture of inquiry in classroom and importance of communication within the group can be easily seen as the crux of these activities. Rather than relying on teacher's unquestionable authority, students in these pedagogic settings propose and 
defend their own views. They also respond thoughtfully to views of others. This process leads them to be a member of the community of inquiry (Goss, 2004). The whole class benefits from sum of cognition as when the class is divided into groups, a new social context was created, in which students get the opportunity to share individual cognition with their peers and arrive at conclusions based on the sum of those cognitions (Slavin, 1995). A new participant structure emerges in classroom where power and authority shift from teacher to the students. It has potential to change the relationship between teacher and learner, between learner and learner and learner and subject matter studied (Wertsch, 1998). Students had developed ways of communicating, reasoning, and providing arguments to defend their ideas as they participate in and contribute to the norms and practices of their learning communities. It was found that learners were able to see themselves as question posers, decision makers and participants of democratic discussion where their views and ideas were heard.

The findings of the present study challenged the prevailing believes of social science teacher and showed that students are cognizant about the social issues such as class, caste, discrimination, poverty etc. The students studying in class six can also articulate their views on various social issues. The new role of the learner as 'negotiator between the self, the learning process and the object of learning showed that the learner is as much a contributor as a gainer in the learning process and thereby he/she learns in an independent way. However, the study raises some questions concerning pedagogic practices of school social science i.e. who decides what is worth teaching? How teachers own biases and beliefs which is the product of his/her socio-cultural experiences influence the learning processes? How the enacted curriculum is different from envisioned curriculum? How to explicate the hidden fabric of learner's socialization which impedes the very essential value of social cohesion? These questions must be taken into account while designing pedagogic setting for teaching Social Science at school level. Issues related to class, caste, gender poverty and power need to bring to forefront of the classroom. A social studies teacher who utilizes learners funds of knowledge will be able to transform the classroom in such a way where multiple facets of social reality is contested and this contestation will further contribute in propagating learners critical literacy. Using learner's fund of knowledge for teaching social science will contribute in developing critical literacy and further will equip learner to appreciate pluralism, consider diversity as an asset, and take an informed position regarding critical social issues.

\section{References}

Bhattacharya, H. (2008). Interpretive research. The Sage Encyclopedia of Qualitative Research Methods. New Delhi: Sage.

Brophy, J. (2002). Social constructivist teaching: affordances and constraints. Boston: Elsevier.

Bruner, J. S. (1996). The culture of education. Cambridge, M.A.: Harvard University Press.

Bryman, A. (2008). Social research methods. New York: Oxford University Press.

Cannella, G. S. \& Reiff, J. C. (1994). Individual constructivist teacher education: teachers as empowered learners. Teacher Education Quarterly, 21 (3), 31-35.

CERID. (1989). Instructional Improvement in Primary Schools. Kathmandu: Author.

Creswell, J. W. (2003). Research design: Qualitative and quantitative approaches (2nd ed.). London: Sage.

College of Education. (1956). Education in Nepal-report of the Nepal National Education Planning Commission. Kathmandu: Author.

Ediger, M. (2000). Psychology in Teaching the Social Studies. Journal of Instructional Psychology, 27(1), 28-36.

Freire, P. (1971). Pedagogy of the oppressed. New York: Seabury Press.

Gonzalez, N. \& Amanti, C. (1992). Funds of knowledge for teaching: using a qualitative approach to connect homes and classrooms. Theory in Practice, 31(2), 132-141

Goss, M. (2004). Learning mathematics in a classroom community of inquiry. Journal for Research in Mathematics Education, 35 (4), 2558-291.

Grix, J. (2004). The foundations of research. London: Palgrave Macmillan. 
High Level National Education Commission (HLNEC). (1999). The Report of High Level National Education Commission. Kathmandu: Author.

Lave, J. \& Wenger, E. (1991). Situated learning-legitimate peripheral participation, New york, U.S.A.: Cambridge University Press.

McLaren, P. (2003). Life in schools: an introduction to critical pedagogy. New York: Pearson.

MOE. (1961). Report of All Round National Education Commission. Kathmandu: Author.

MOE. (1971). Report of the National Education System Plan. Kathmandu: Author.

MOE. (1999). BPEP-II Programme Implementation Plan 1999-2004 (Main Report). Kathmandu: Author.

MOE. (2009). School Sector Reform Plan 2009-2015. Kathmandu: Author.

MOEC. (1991). The Basic and Primary Education Master Plan 1991-2001. Kathmandu: Author.

MOES. (2003). Education for All National Plan of Action Nepal (2001-2015). Kathmandu: Author.

MOES. (2005). National Curriculum Framework for School Education (pre-primary to 12) in Nepal. Kathmandu: Author.

Moll, L. C., Amanti, C., Neff, D. \& Gonzalez, N. (1992). Funds of knowledge for teaching: using a qualitative approach to connect homes and classrooms. Theory in Practice, 31(2), 132-141.

NEC. (1992). Report of National Education Commission. Kathmandu: Author.

Nuthall, G. (2000). The Role of Memory in Acquisition and Retention of Knowledge in Science and Social Studies Units. Cognition and Instruction, 18 (1), 83-139.

Roberta McKay, (Summar, 1995). Brain-based learning: support for an inquiry curriculum. Canadian Social Studies, 29(4), 128-129.

Rogoff, B. (1998). Cognition as a collaborative process. In D. Kuhn \& R. S. Siegler (Eds.), Handbook of child psychology (pp. 679-744). New York: John Wiley.

Slavin, R. E. (1995). Cooperative learning and intergroup relations. In J. A. Banks (Ed.), Handbook of multicultural education (pp. 628-634). New York: McMillan.

Smith, J. and Heshusius, L. (1986). Closing down the conversation: the end of the quantitative-qualitative debate among educational inquirers. Educational Researcher, 15(1) 4-12.

Richardson, V. (1970). Constructivist teaching and teacher education: theory and practice. In V. Richirdson (Ed.), Constructivist Teacher Education: Building a New World of Understandings (pp.3-14). Washington, D. C.: Falmer Press.

Velez-Ibanez, C. \& Greenberg, J. (1992). Formation and transformation of funds of knowledge among U.S.Mexican households. Anthropology \& Education Quarterly, 23(4), 313-335.

Vygotsky, L. (1987). Mind in society: the development of higher psychological processes. Cambridge, M.A., Harvard University Press.

Wertsch, J. (1997). Mind in action. New York: Oxford University Press.

Zevin, J. (2000). Social studies for the twenty-first century: methods and materials for teaching in middle and secondary schools. New York: Longman. 